Note

\section{A New Sample Preparation Method Using Borate Fusion for X-ray Fluorescence Analysis of Vanadium, Chromium, Cobalt, Molybdenum, and Tungsten in High-speed Steel}

\section{Kenichi NAKAYAMA* and Kazuaki WAGATSUMA}

Institute for Materials Research, Tohoku University, Katahira, Aoba-ku, Sendai, 980-8577 Japan.

(Received on July 15, 2016; accepted on August 9, 2016)

This paper suggests a rapid preparation for quantitative analysis of a type of high-alloyed steel in wavelength dispersive X-ray fluorescence analysis of the allying elements (vanadium, chromium, cobalt, molybdenum, and tungsten). The samples were decomposed with nitric acid and hydrofluoric acid, and then fused with an alkali flux of lithium tetraborate. The synthetic standards for the quantification were prepared by using metal standard solutions of analytes and iron as a matrix component. Analytical results based on the following methods were successfully obtained: a milligrambased calibration with six synthetic standards by using conventional linear calibration curves, and a corrected fundamental parameter calculation with the same synthetic standards. The present method enabled rapid sample preparation and thus simplified an analytical procedure for high-speed steel compared to the conventional wet analysis including inductively coupled plasma atomic emission spectrometry.

KEY WORDS: X-ray fluorescence spectrometry; synthetic standard specimen; metal standard solution; fused glass bead.

\section{Introduction}

A kind of high-alloyed steels, which is particularly designed for cutting tools or heat jigs, is called high-speed steel or tool steel. This special steel contains various alloying metals (chromium, molybdenum, tungsten, etc.) to maintain its mechanical and chemical properties under the severe working conditions. For instance, tungsten is added to the high-speed tool steel to improve abrasion and heating resistances. ${ }^{1)}$ It is thus essential that such alloying metals should be quantified with high precision for quality control of the manufactured materials as well as saving of the rare metals. Authors have suggested a sample preparation method based on borate fusion ${ }^{2)}$ for tungsten determination in high-speed steel by using X-ray fluorescence (XRF) method..$^{3)}$ This method makes possible to prepare a specimen within $30 \mathrm{~min}$, whereas solution preparation for inductively coupled plasma atomic emission spectrometry is time-consuming (about half a day) to obtain stable sulfuric and phosphoric acids solution ${ }^{4)}$ with no precipitation of

\footnotetext{
* Corresponding author: E-mail: ken1naka@imr.tohoku.ac.jp DOI: http://dx.doi.org/10.2355/isijinternational.ISIJINT-2016-435
}

tungsten. Furthermore, the present procedure enables us to prepare synthetic calibration standards with metal standard solution in the same way as high-speed steel, which may be applied to various applications for different kinds of analytes, over a wide range of contents, and independent of the composition similarity between the sample and standards.

The present paper represents an XRF procedure for the determination of alloying elements (vanadium, chromium, cobalt, molybdenum, and tungsten) in a high-speed steel sample. In addition, a correction method using fundamental parameters was modified by using the synthetic standards containing these alloying elements.

\section{Experimental}

Glass bead specimens were prepared by using a platinum crucible containing 5 mass $\%$ of gold heated on a Meker burner. About 10-12 mg of each high-speed steel specimen was weighed. In the platinum crucible, the steel sample was decomposed by nitric and hydrofluoric acids and fused together with $4.00 \mathrm{~g}$ of lithium tetraborate as an alkali flux and lithium chloride as an exfoliation agent as published in an article. ${ }^{3)}$ The following standard solutions of each analyte were prepared: (1) $5.0 \mathrm{mg} \mathrm{cm} \mathrm{cm}^{-3}$ of vanadium nitric-acid solution of pure-metal, (2) $4.0 \mathrm{mg} \mathrm{cm}^{-3}$ of chromium solution which was replaced by nitric acid after the pure-metal had been decomposed using hydrochloric acid, (3) $50.0 \mathrm{mg}$ $\mathrm{cm}^{-3}$ of iron nitric-acid solution of pure-metal, (4) 10.0 $\mathrm{mg} \mathrm{cm} \mathrm{cm}^{-3}$ of cobalt nitric-acid solution of pure-metal, (5) $10.0 \mathrm{mg} \mathrm{cm}^{-3}$ of molybdenum aqua regia solution of puremetal, and (6) $15.0 \mathrm{mg} \mathrm{cm}^{-3}$ of tungsten aqueous solution of sodium tungstate. Six calibration standards containing totally $11.0 \mathrm{mg}$ of added components were prepared, as shown in Table 1. The analytes were added by using a variable micropipette for 20 to $200 \mathrm{~mm}^{3}$. Wavelength dispersive $\mathrm{X}$-ray fluorescence method was employed for the present measurements. An X-ray spectrometer of ZSX Primus II (Rigaku Corp.; Tokyo, Japan) was operated under the following conditions: a rhodium X-ray target at $50 \mathrm{kV}$ and 60 $\mathrm{mA}$ excitation, a $\operatorname{LiF}(200)$ analyzing crystal, a scintillation counter having $30 \mathrm{~mm}$ in a measuring diameter, an a copper filter for molybdenum $\mathrm{K} \alpha$. The counting time was set to be $20 \mathrm{~s}$ for vanadium $\mathrm{K} \alpha$ and chromium $\mathrm{K} \alpha$, and $10 \mathrm{~s}$ for cobalt $\mathrm{K} \alpha$, molybdenum $\mathrm{K} \alpha$, and tungsten $\mathrm{L} \alpha$ in each measurement of the peak and two background positions.

Table 1. Added analytes and matrix iron (in $\mathrm{mg}$ ) in calibrating standards with $4.00 \mathrm{~g}$ of lithium tetraborate.

\begin{tabular}{lllllll}
\hline & V & Cr & Co & Mo & W & Fe \\
\hline No. 1 & 0.30 & 0.60 & 0 & 0.30 & 0 & 9.80 \\
No. 2 & 0.15 & 0 & 0.30 & 0.90 & 0.50 & 9.15 \\
No. 3 & 0.75 & 0.15 & 0.90 & 0 & 1.00 & 8.20 \\
No. 4 & 0 & 0.30 & 1.50 & 0.60 & 1.50 & 7.10 \\
No. 5 & 0.45 & 0.45 & 0.60 & 1.50 & 2.00 & 6.00 \\
No. 6 & 0.60 & 0.75 & 1.20 & 1.20 & 2.50 & 4.75 \\
\hline
\end{tabular}




\section{Results and Discussion}

The calibration standards gave excellent linear calibration curves (correlation coefficient: $r>0.9996$ ). The calibration curves were obtained by using a least-squares method of regression of the XRF intensity on the amount of analytes added to the synthetic standard. The software installed in the XRF instrument was not used for this calculation. Applicable content ranges ${ }^{3)}$ in the present calibration were estimated as follows: 0.1 to 6.8 mass $\%$ of vanadium, 0.3 to 6.8 mass $\%$ of chromium, 0.4 to 13.6 mass $\%$ of cobalt, 0.2 to 13.6 mass $\%$ of molybdenum, and 0.7 to 22.7 mass $\%$ of tungsten. This calibration was applicable to a commercial high-speed steel containing 1 to 19 mass $\%$ of tungsten. ${ }^{1)}$ Vanadium $\mathrm{K} \beta$ line overlaps with chromium $\mathrm{K} \alpha$ line; therefore, the corrected $\mathrm{XRF}$ intensity of chromium $\mathrm{K} \alpha$ line was calculated by the following equation: $I_{\mathrm{Cr}-\mathrm{K} \alpha}=I_{\mathrm{Cr}-\mathrm{K} \alpha}+\mathrm{V}-\mathrm{K} \beta-k I_{\mathrm{V}-\mathrm{K} \alpha}$, where $I$ is XRF intensity, and $k$ is a correction factor obtained by measuring glass bead specimens containing only vanadium and iron as the matrix component. Several certified reference materials (CRMs) were determined to validate the present XRF procedure. The CRMs of high-speed steel issued by the Japanese Iron and Steel Federation were used: 607-9, 609-10, 610-10, and 611-11. Four glass beads were prepared for each CRM sample. Excellent analytical results were obtained as summarized in Table 2. By using the present method, a rapid XRF determination based on individual calibration curves for the alloying elements could be carried out.

A conventional calibration method using glass beads was based on the concentration of each analyte element, where the weighed sample should be equally diluted at the same dilution ratio. On the other hand, glass beads in our method were similar to aqueous solutions in a volumetric flask. Alloying elements of an order of mg were uniformly mixed with $4.00 \mathrm{~g}$ of borate glass. In this case, X-ray absorption and enhancement effects were negligibly small, and then the very large dilution (flux/steel > 300) enabled the milligrambased calculation.

In spite of such large dilution, a standardless calculation which was operated with a software in the XRF instrument gave erroneous results (Table 2). This is because the glass beads were regarded as a bulk specimen for lower energy fluorescent $\mathrm{X}$-rays such as vanadium $\mathrm{K} \alpha$, chromium $\mathrm{K} \alpha$, iron $\mathrm{K} \alpha$, cobalt $\mathrm{K} \alpha$ and tungsten $\mathrm{L} \alpha$ lines, whereas the those were also regarded as a thin-film specimen for higher energy fluorescent X-rays like molybdenum $\mathrm{K} \alpha$ line, whose analytical depth was more than $10 \mathrm{~mm}$. The prepared glass beads had about $2 \mathrm{~mm}$ in thickness. Then, very faint XRF intensity of molybdenum $\mathrm{K} \alpha$ would give erroneous results in the standardless determination based on a qualitative XRF spectrum. On the other hand, we successfully obtained analytical results with the calibration curve by preparing sample and standard specimens having the same thickness.

The results of the standardless calculation had constant biases (Fig. 1). Then, the following equation was recommended to correct the quantification calculation: $E=b A$, where $E$ is an estimated amount by standardless calculation (in mg), $b$ is constant, and $A$ is an amount of added components in synthetic standard (in $\mathrm{mg}$ ). Obtained $b$ constants were 0.895 for vanadium, 1.004 for chromium, 1.025 for iron, 1.014 for cobalt, 0.798 for molybdenum, and 1.135 for tungsten. The correction was successfully applied to highspeed steel samples for the analytical validation (Table 2). The calibration curves by using synthetic standards contributed to the most reliable results, whereas the fundamental parameter calculation with the synthetic standard might rapidly gave good results for the XRF applications using an energy dispersive instrument.

Table 2. Analytical results (in $\operatorname{mass} \%, n=4$; with standard deviation) of alloying elements in certified reference materials of high-speed steel.

\begin{tabular}{|c|c|c|c|c|c|c|c|c|c|c|c|c|}
\hline & \multicolumn{4}{|c|}{ Vanadium } & \multicolumn{4}{|c|}{ Chromium } & \multicolumn{4}{|c|}{ Cobalt } \\
\hline & \multicolumn{2}{|c|}{ FP calculation } & \multirow[b]{2}{*}{$\begin{array}{l}\text { Using } \\
\text { Calibration } \\
\text { curve }\end{array}$} & \multirow[b]{2}{*}{$\begin{array}{l}\text { Certified } \\
\text { value }\end{array}$} & \multicolumn{2}{|c|}{ FP calculation } & \multirow[b]{2}{*}{$\begin{array}{l}\text { Using } \\
\text { Calibration } \\
\text { curve }\end{array}$} & \multirow[b]{2}{*}{$\begin{array}{l}\text { Certified } \\
\text { value }\end{array}$} & \multicolumn{2}{|c|}{ FP calculation } & \multirow[b]{2}{*}{$\begin{array}{c}\text { Using } \\
\text { Calibration } \\
\text { curve }\end{array}$} & \multirow[b]{2}{*}{$\begin{array}{c}\text { Certified } \\
\text { value }\end{array}$} \\
\hline CRMs & $\begin{array}{l}\text { Without } \\
\text { standard }\end{array}$ & $\begin{array}{c}\text { With } \\
\text { synthetic } \\
\text { standards }\end{array}$ & & & $\begin{array}{l}\text { Without } \\
\text { standard }\end{array}$ & $\begin{array}{c}\text { With } \\
\text { synthetic } \\
\text { standards }\end{array}$ & & & $\begin{array}{l}\text { Without } \\
\text { standard }\end{array}$ & $\begin{array}{c}\text { With } \\
\text { synthetic } \\
\text { standards }\end{array}$ & & \\
\hline $607-9$ & 0.81 & $0.90 \pm 0.05$ & $0.92 \pm 0.04$ & 0.90 & 3.99 & $3.97 \pm 0.15$ & $4.00 \pm 0.10$ & 4.00 & 4.59 & $4.53 \pm 0.10$ & $4.50 \pm 0.02$ & 4.63 \\
\hline $610-10$ & 3.03 & $3.38 \pm 0.07$ & $3.25 \pm 0.08$ & 3.25 & 3.84 & $3.83 \pm 0.07$ & $3.89 \pm 0.11$ & 3.99 & 10.0 & $9.88 \pm 0.19$ & $9.45 \pm 0.18$ & 9.60 \\
\hline $611-11$ & 2.08 & $2.32 \pm 0.10$ & $2.18 \pm 0.01$ & 2.14 & 4.07 & $4.05 \pm 0.12$ & $4.01 \pm 0.04$ & 4.06 & 0.40 & $0.39 \pm 0.02$ & $0.27 \pm 0.02$ & 0.282 \\
\hline
\end{tabular}

\begin{tabular}{|c|c|c|c|c|c|c|c|c|}
\hline \multirow[b]{3}{*}{ CRMs } & \multicolumn{4}{|c|}{ Molybdenum } & \multicolumn{4}{|c|}{ Tungsten } \\
\hline & \multicolumn{2}{|c|}{ FP calculation } & \multirow[b]{2}{*}{$\begin{array}{c}\text { Using } \\
\text { Calibration } \\
\text { curve }\end{array}$} & \multirow[b]{2}{*}{$\begin{array}{c}\text { Certified } \\
\text { value }\end{array}$} & \multicolumn{2}{|c|}{ FP calculation } & \multirow[b]{2}{*}{$\begin{array}{c}\text { Using } \\
\text { Calibration } \\
\text { curve }\end{array}$} & \multirow[b]{2}{*}{$\begin{array}{c}\text { Certified } \\
\text { value }\end{array}$} \\
\hline & $\begin{array}{l}\text { Without } \\
\text { standard }\end{array}$ & $\begin{array}{c}\text { With } \\
\text { synthetic } \\
\text { standards }\end{array}$ & & & $\begin{array}{l}\text { Without } \\
\text { standard }\end{array}$ & $\begin{array}{c}\text { With } \\
\text { synthetic } \\
\text { standards }\end{array}$ & & \\
\hline $607-9$ & 0.15 & $0.19 \pm 0.09$ & $0.23 \pm 0.01$ & 0.278 & 19.4 & $17.1 \pm 0.2$ & $16.9 \pm 0.1$ & 17.29 \\
\hline $609-10$ & 3.61 & $4.53 \pm 0.08$ & $4.77 \pm 0.06$ & 4.85 & 7.21 & $6.35 \pm 0.16$ & $6.17 \pm 0.05$ & 6.11 \\
\hline $610-10$ & 2.19 & $2.74 \pm 0.08$ & $2.91 \pm 0.06$ & 3.07 & 10.5 & $9.25 \pm 0.17$ & $8.90 \pm 0.14$ & 9.03 \\
\hline $611-11$ & 3.58 & $4.49 \pm 0.08$ & $4.77 \pm 0.12$ & 4.91 & 7.09 & $6.25 \pm 0.18$ & $6.09 \pm 0.05$ & 6.10 \\
\hline
\end{tabular}

CRMs, Certified reference materials of high-speed steel issued by The Japanese Iron and Steel Federation. 

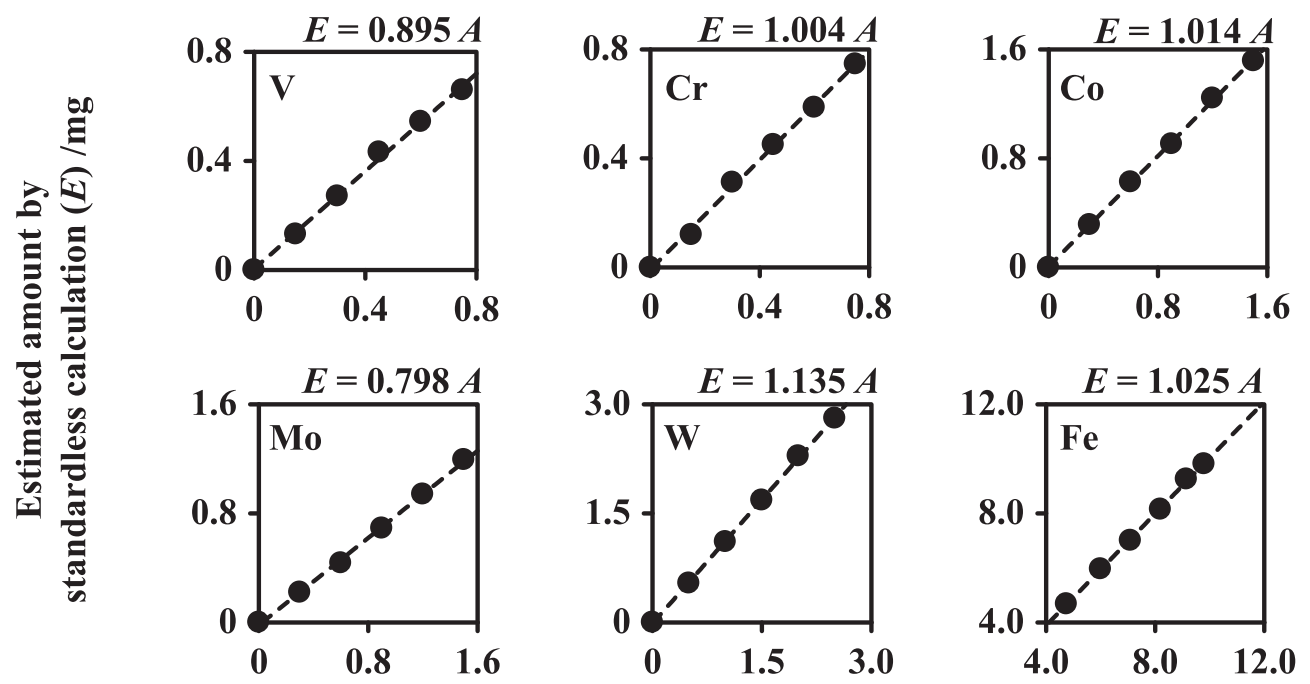

\section{Amount $(\boldsymbol{A}) / \mathrm{mg}$}

Fig. 1. Added amount of analytes and matrix iron in synthetic standards with estimated amount by standardless calculation with used X-ray fluorescence instrument.

\section{Conclusions}

Alloying elements of vanadium, chromium, cobalt, molybdenum, and tungsten in high-speed steel were determined by using wavelength dispersive X-ray fluorescence analysis with synthetic standards. The synthetic standards containing five constituent elements and the matrix iron were prepared with metal standard solutions to obtain normal linear calibration curves. These standards were also used to correct analytical results obtained from fundamental parameter calculation.

\section{Acknowledgements}

This work was supported by the 24th ISIJ Research Promotion Grant.

\section{REFERENCES}

1) JIS G 4403: 2006, High speed tool steels.

2) K. Nakayama and K. Wagatsuma: ISIJ Int., 56 (2016), 1114.

3) K. Nakayama and K. Wagatsuma: Anal. Sci., 31 (2015), 851.

4) JIS G 1258-2: 2014, Iron and steel-ICP atomic emission spectrometric method-Part 2: Determination of various elements-Decomposition with phosphoric and sulfuric acids. 